\title{
Lessons Learned from Government-Academe-Civil Society Partnership to Improve the Assessment and Management of Drug Dependence in the Philippines
}

\author{
Carl Abelardo T. Antonio, ${ }^{1}$ Jonathan P. Guevarra, ${ }^{2}$ Lolita L. Cavinta, ${ }^{3}$ Nina G. Gloriani, ${ }^{3}$ Jasmin T. Peralta, ${ }^{4}$ \\ Ma. Lourdes Reyes-Sare, ${ }^{5}$ Francis Emmanuel A. Galera, ${ }^{4}$ Salvador Benjamin D. Vista ${ }^{6,7}$ and Manuel C. Panopio ${ }^{8}$ \\ ${ }^{1}$ Department of Health Policy and Administration, College of Public Health, University of the Philippines Manila \\ ${ }^{2}$ Department of Health Promotion and Education, College of Public Health, University of the Philippines Manila \\ ${ }^{3}$ Department of Medical Microbiology, College of Public Health, University of the Philippines Manila \\ ${ }^{4}$ Department of Health, Republic of the Philippines \\ ${ }^{5}$ National Center for Mental Health, Mandaluyong City, Philippines \\ ${ }^{6}$ Group for Addiction Psychiatry of the Philippines, Pasig City, Philippines \\ ${ }^{7}$ Department of Psychiatry and Behavioral Medicine, College of Medicine and Philippine General Hospital, University of the Philippines Manila \\ ${ }^{8}$ Philippine College of Addiction Medicine, Quezon City, Philippines
}

\begin{abstract}
Objective. This paper presents the experiences of, and lessons learnt from, a seven-year government-academecivil society collaboration in the development, implementation, and evaluation of a training program for Filipino physicians and rehabilitation practitioners on the management of drug dependence.

Methods. Review of memoranda, records, and reports relevant to the initiation and implementation of the training activity. Where relevant, we also perused internal notes and minutes of meetings written by the authors, who are also members of the training team.
\end{abstract}

Results. A tripartite collaboration between government, academe, and professional organizations developed a training program on the management of drug dependence for physicians and rehabilitation practitioners. Learnercentered approaches to education were adopted in the delivery of training content. Participation in the training is a prerequisite for government accreditation as rehabilitation professionals. A ladderized approach to the training was adapted, with participants first obtaining a broad introduction to the program, followed by in-depth focus on the assessment and management of drug dependency. This was done as a response to the perception that a single, twoweek training program is insufficient to fully capacitate physicians and rehabilitation practitioners with the requisite knowledge and skills necessary to manage persons with drug dependence. Future plans include an executive course for established practitioners, and a course on community-based management of drug dependency.

Conclusion. The current perspective on drug use and dependence is transitioning from a politico-legal issue to a public health concern. Attaining the sustainable development goals in 2030 will necessitate the development of a cadre of professionals who are, among others, capable of assessing and treating persons who suffer from drug dependence. The Philippine experience may serve as a model for other countries struggling with the drug menace.

Key Words: drug use; drug dependence; substance-related disorders; substance abuse treatment centers; Philippines

Poster presented at the 48th Asia Pacific Academic Consortium for Public Health Conference, Teikyo University, September 16 - 19, 2016, Tokyo, Japan.

Corresponding Author: Carl Abelardo T. Antonio, MD, MPH Department of Health Policy and Administration

College of Public Health

University of the Philippines Manila

625 Pedro Gil Street, Ermita, Manila 1000 Philippines

Telephone: +6323428932

Email: ctantonio@up.edu.ph

\section{INTRODUCTION}

The worldwide burden of disease attributable to the use of illicit drugs, both as a medical disorder and risk factor, has substantially increased between 1990 and 2013. ${ }^{1,2}$ The criminalization of drug use and dependence in the current global policy regime, however, has resulted to, among others, the neglect of most aspects of health services related to the condition. ${ }^{3}$ Thus, country-specific treatment practice recommendations are relatively recent (i.e., United 
States of America in 20054; United Kingdom in 20125), and international standards, crafted in 2015 , are still to be field-tested. ${ }^{6}$

Meanwhile, there is growing global recognition for the need to strengthen the prevention and treatment of substance use disorders. The United Nations (UN) General Assembly adopted in September 2015 the agenda for sustainable development, which includes as a goal, among others, the strengthening of "prevention and treatment of substance abuse, including narcotic drug abuse and harmful use of alcohol."” A 2016 draft UN resolution on the world drug problem further affirmed the need to capacitate health professionals in delivering treatment and prevention programs within the broader context of the national drug control policy. ${ }^{8}$

This paper presents the experiences of, and lessons learnt from, a seven-year government-academe-civil society collaboration in the development, implementation, and evaluation of a training program for Filipino physicians and rehabilitation practitioners on the management of drug dependence.

\section{METHODS}

We reviewed memoranda, records, and reports relevant to the initiation and implementation of the training activity. Where relevant, we also perused internal notes and minutes of meetings written by the authors, who are also members of the training team. From these documents, we abstracted data and generated information on a) the rationale for the collaboration; b) approach to the training; and c) lessons learned from the tripartite partnership.

\section{RESULTS}

\section{Local Setting}

There are an estimated 1.3 million drug users in the Philippines in 2012. ${ }^{9}$ While this represents an 18\% decline from national prevalence data obtained in $2008^{10}$, drug use disorders still account for $2.45 \%$ of total years lived with disability, and $1.21 \%$ of total disability-adjusted life years, among all disease conditions in the country. ${ }^{11}$

Drug abuse prevention in the Philippines is guided by the overarching framework laid out in a statute enacted in 1972, and expanded thirty years later. ${ }^{12,13}$ Voluntary or compulsory (i.e., through a lawful court order) treatment and rehabilitation for drug dependence is the prevailing policy in the country. However, following promulgation of the 2002 comprehensive dangerous drugs statute, responsibility for the provision of treatment and rehabilitation services has shifted from a law enforcement agency under the Department of Justice, to the Department of Health (DOH). Furthermore, there was recognition that the responsibility for provision of treatment and rehabilitation rests not solely with physicians, but requires a team approach with involvement of nurses, psychologists, social workers, and counsellors , among others (collectively referred to in this paper as rebabilitation practitioners).${ }^{14}$ Consequently, the accreditation of healthcare providers for such treatment and rehabilitation services was also transferred from the Dangerous Drugs Board (DDB), the national drug control policy-making and coordinating agency, to the $\mathrm{DOH}$.

While there was already a cadre of physicians trained on the management of drug dependence organized by the DDB, the post-2002 landscape presented three challenges for the DOH. First was the absence of competencies and standardized trainings on management of drug dependence. Expected learning outcomes, and the relevant theoretical and operational framework, were not articulated and documented, resulting to disparities in the content and methods of training activities offered at that time. Second, and as a corollary of the first, regulation of rehabilitation centers were hampered by the deficiency in clinical practice guidelines or quality standards. Thus, high variability in practice, especially between public and private facilities as well as those between psychiatrists and general practitioners, was observed.

Meanwhile, DDB accreditation was provisionally extended until 2008, after which physicians and practitioners were to seek re-accreditation from the $\mathrm{DOH}$ under the new governance framework.

It was in this context that a government-academe-civil society partnership was forged with the aim of capacitating physicians and rehabilitation professionals on the assessment and management of drug dependence.

\section{Approach}

The $\mathrm{DOH}$, having identified a gap that will hinder the attainment of the goals under the Dangerous Drugs Abuse Prevention and Treatment Program, entered into a strategic alliance with an academic institution (College of Public Health, University of the Philippines Manila [CPH]) and two professional organizations (Group for Addiction Psychiatry of the Philippines [GAPP] and Philippine College of Addiction Medicine [PCAM]) to develop and implement a training program on the management of drug dependence.

Overall direction is steered by the $\mathrm{DOH}$ to ensure that training activities and outcomes are aligned with programmatic and national policy directives. Adherence to current evidence-based practice in addiction psychiatry is ensured through participation of GAPP and PCAM, while $\mathrm{CPH}$ provides technical assistance on training design enhancement, implementation, and evaluation of the conduct of the training program.

The primary purpose of the training is to capacitate physicians and rehabilitation practitioners on the knowledge, assessment and diagnosis, management and jurisprudence regarding drug dependence. Target participants are professionals working in public and private rehabilitation centers and hospitals, although persons from agencies that also cater to drug dependents (e.g., DDB, Bureau of Jail Management and Penology, Parole and Probation 
Administration, etc.) have also been involved in the training activity.

A ladderized approach was adopted for the training. All professionals undergo a basic training course (Level 1), which provides an overview of the assessment and management of drug dependence. This is followed by an advanced course focusing on in-depth discussion and mentored practice on assessment (Level 2a) and management (Level 2b). While physicians and other rehabilitation practitioners are trained separately for Level 1, a team approach (i.e., a group composed of a physician, nurse, psychologists and social worker from a single facility) was required for Level $2 \mathrm{a}$ and $2 \mathrm{~b}$, as trainee evaluation involves assessment and management of actual patients admitted in their respective rehabilitation facilities.

Learner-centered approaches to education were adopted by the collaboration. Training content is delivered through lectures, small group discussions, workshops, role playing, demonstration-return demonstration, field exposure, case analysis, and mentoring.

Context-specific considerations (i.e., local culture, social norms) were taken into account in the preparation of learning materials.

\section{DISCUSSION: LESSONS LEARNED}

As a result of this tripartite collaboration, 161 physicians and 190 rehabilitation practitioners were trained, and eventually accredited, by the DOH between 2009 and 2015 . Sixteen training courses were conducted with funding from the $\mathrm{DOH}$, and co-payment from the participant or their organization. Design, curricula, modules, and evaluation materials for the two Level 1 and Level 2a training have been produced and refined, while those for $2 \mathrm{~b}$ are still under development. Likewise, plans are being made for the institution of a training for community-based rehabilitation, as well as an executive course for established practitioners. The training activity has been institutionalized, having been recognized by the $\mathrm{DOH}$ as the only training program on drug dependence management that will satisfy governmental requirements for professional and institutional accreditation.

Three crucial lessons can be gleaned from this sevenyear collaborative experience on the development and implementation of a training program on the assessment and management of drug dependence.

First, involvement of program managers, professional organizations, and educators is important in the development of an effective training activity that is linked to accreditation and national practice standards. Congruence of content with state policy, current evidence-based practice, pragmatic considerations based on field experience, and educational and training frameworks will only take place when government, academe and professional organizations actively take part in the development of the curriculum. The alternative scenarios when these stakeholders conceptualize training activities individually are either a) a heavy focus on technical or clinical aspects of drug dependence to the disadvantage of programmatic or policy considerations; or b) an undue focus on content or subject area without proper consideration of method of delivery and evaluation.

Second, continual refinement and adaption of a training program based on needs of program participants; results of formal and informal evaluation; and the state-of-the-art and state-of-the-science should be the norm rather than an exceptional state. The use of a ladderized approach to training delivery, for example, was a response to the perception that a two-week training program is insufficient to fully capacitate physicians and rehabilitation practitioners with the requisite knowledge and skills necessary to manage persons with drug dependence. Provision of separate entry-level training courses for physicians and rehabilitation practitioners was also thought to be advantageous as a more in-depth discussion of the clinical aspects of drug dependence management can be offered to medical doctors, information that may not truly be useful and relevant for rehabilitation practitioners when they return to their workplaces.

Finally, institutional participation, commitment and support help assure sustainability of an enterprise. In the course of this seven-year collaboration, some of the personalities who were involved during the training conceptualization either transferred to another unit, retired, or voluntarily withdrew from their respective organizations. Leadership of the two professional organizations likewise changed following their own internal election rules. Anchoring the undertaking at the organizational rather than the individual level, thus, insulated the training program from disruptions or changes internal to the participating institutions.

\section{CONCLUSION}

The current perspective on drug use and dependence is transitioning from a politico-legal issue to a public health concern. Attaining the sustainable development goals in 2030 will necessitate the development of a cadre of professionals who are, among others, capable of assessing and treating persons who suffer from drug dependence. The Philippine experience may serve as a model for other countries struggling with the drug menace.

\section{Statement of Authorship}

CTA conceptualized the project. CTA and JPG prepared the first draft. CTA finalized the manuscript based on comments from authors and reviewer feedback. All other authors provided data, reviewed results, and/or contributed to the report. All authors approved the final version submitted.

\section{Author Disclosure}

All authors are part of the organizing team and/or training team for the Training Course for the Assessment and Management of Drug Dependence, which is the subject of this paper. 


\section{Funding Source}

No external funding.

\section{REFERENCES}

1. Global Burden of Disease Study 2013 Collaborators. Global, regional, and national incidence, prevalence, and years lived with disability for 301 acute and chronic diseases and injuries in 188 countries, 1990-2013: a systematic analysis for the Global Burden of Disease Study 2013. Lancet. 2015;386(9995):743-800. doi: 10.1016/S01406736(15)60692-4.

2. GBD 2013 Risk Factors Collaborators, Forouzanfar MH, Alexander L, Anderson HR, et al. Global, regional, and national comparative risk assessment of 79 behavioural, environmental and occupational, and metabolic risks or clusters of risks in 188 countries, 19902013: a systematic analysis for the Global Burden of Disease Study 2013. Lancet. 2015;386(10010):2287-323. doi: 10.1016/S01406736(15)00128-2.

3. Csete J, Kamarulzaman A, Kazatchkine M, et al. Public health and international drug policy. Lancet. 2016;387(10026):1427-80. doi: 10.1016/S0140-6736(16)00619-X.

4. National Quality Forum. Workshop Proceedings: Evidence-Based Treatment Practices for Substance Use Disorders. Washington, DC: National Quality Forum; 2005.

5. National Institute for Health and Care Excellence. NICE quality standard [QS23]: Drug use disorders in adults [Online]. 2012 Nov [cited 2016 Apr 24]. Available from https://www.nice.org.uk/ guidance/qs23.
6. United Nations Office on Drugs and Crime and World Health Organization. International Standards for the Treatment of Drug Use [Online]. 2016 Mar [cited 2016 April 24]. Available from https:// www.unodc.org/documents/commissions/CND/CND_Sessions/ CND_59/ECN72016_CRP4_V1601463.pdf.

7. Transforming our world: the 2030 Agenda for Sustainable Development (A/RES/70/1). 2015 Oct 21.

8. Our joint commitment to effectively addressing and countering the (A/S-30/L.1). 2016 Apr 14.

9. Dangerous Drugs Board. 2012 Researches: 2012 Nationwide Survey on the Current Nature and Extent of Drug Abuse in the Philippines [Online]. c 2012 [cited 2016 Mar 01]. Available from http://www. ddb.gov.ph/research-statistics/research/45-research-and-statistics/882012-researches\#a.

10. Dangerous Drugs Board. 2008 National Household Survey on the Nature and Extent of Drug Abuse in the Philippines. Quezon City: Dangerous Drugs Board; 2008.

11. Institute for Health Metrics and Evaluation. GBD Compare [Online]. c 2015 [cited 2016 Mar 01]. Available from http://vizhub.healthdata. org/gbd-compare.

12. Congress of the Philippines, Republic of the Philippines. Republic Act No. 6425, The Dangerous Drugs Act of 1972. 1972 Apr 04.

13. Congress of the Philippines, Republic of the Philippines. Republic Act No. 9165, Comprehensive Dangerous Drugs Act of 2002. 2002 Jun 07.

14. Dangerous Drugs Board. Board Regulation No. 4, series of 2003, Implementing Rules and Regulations Governing Accreditation of Drug Abuse Treatment and Rehabilitation Centers and Accreditation of Center Personnel. 2003 Jul 11.

\title{
Have you read the current trends in
} Medical and Health Research in the Philippines?

\section{Acta Medica Philippina The National Health Science Journal}

\author{
Access Online: www.actamedicaphilippina.org
}

